\section{Structural analysis of factors that influence professional learning communities in Korean elementary schools}

Kyoung-Oh Song ${ }^{a}$, Jinyoung Choi ${ }^{\mathrm{b}}$

\author{
Received: 27 July 2017 \\ Revised: 02 Sept. 2017 \\ Accepted: 12 Sept. 2017 \\ ISSN: 1307-9298 \\ Copyright (C) IEJEE \\ www.iejee.com
}

\begin{abstract}
Professional Learning Communities (PLCs) are an important strategy for innovation in schools, and they are receiving considerable attention from scholars and educators alike. The present study aimed to examine the effect of PLCs on schools' effectiveness and to investigate the social, organizational, and structural factors that can promote these learning communities. The survey for this study was completed by 375 teachers from 40 elementary schools in the Seoul Metropolitan Area of South Korea, and their responses were analyzed to test the hypothesized model. The results of the structural equation modeling indicated that PLCs were strongly and directly related to elementary schools' effectiveness and that principals' leadership and supportive relationships among teachers were the important factors that influenced PLCs. Based on the results of this study, several implications are discussed.
\end{abstract}

Keywords: Professional learning community, school effectiveness, principal leadership, supportive relationships

\section{Introduction}

In recent years, there has been a worldwide emphasis on the importance of cooperative relationships among teachers for reforming schools, along with great academic interest in professional learning communities (PLCS). In the current field of education, it is hoped that PLCs based on sharing values about learning and abundant discussion and collaboration on teaching activities will bring about significant changes in teaching activities and student learning. Little (2003) presents a body of evidence to show that teachers have more learning opportunities and strive to improve their instructional learning in PLCS that respect their experimental spirit and support peer collaboration in attempting new instructional learning activities. McLaughlin and Talbert (2001) points out that not all teacher communities have a positive impact on changes in schools and maintains that teachers attempt to organize effective teaching-learning methods in PLCS that favor innovation and continuous exploration and that encourage teachers to collaboratively design and implement new teaching-learning activities. Recently, researchers (e.g., Barton \& Stepanek, 2012; Harris \& Jones, 2010; Katz \& Earl, 2010) have found evidence that PLCs can have positive effects not only on teacher's performance in the classroom but also on students' academic performance.
With the active exploration of PLCs by academics in other countries, academic interest in them has gradually been increasing over the last few years in Korea as well. Since the concept of PLCs was introduced (e.g., Seo, 2009), researchers are discussing the possibility of enhancing teachers' professionalism through PLCs and conducting studies in the Korean context on the differences PLCs can make to classroom activities (Song \& Choi, 2010). However, research on PLCs in Korea remains limited. In particular, virtually nothing is known about the factors that can influence PLCs in the context of Korean schools. In order to galvanize the implementation of PLCs, there needs to be persistent application and verification of them in the actual circumstances that exist in Korean schools.

For this study, we assumed that PLCs in schools have considerable effects not just on teachers' job satisfaction but also on the changes that take place in the schools. If PLCs contribute to positive changes in schools, educational policymakers and school administrators should take interest in expanding their use in schools and provide them with substantial support. Moreover, by examining the factors that affect PLCs, we suggest to education researchers that it is necessary to emphasize internal school factors including teachers' social relationships in their discussions. Given this understanding of the issues at stake, we examined the

\footnotetext{
${ }^{a}$ Chosun University, Republic of Korea, E-mail: k5song@chosun.ac.kr

${ }^{b}$ Corresponding author: Jinyoung Choi, Ewha Womans University, Department of Elementary Education, Education Building A \#411, 52, Ewhayeodae-gil, Seodaemun-gu, Seoul, Republic of Korea. E-mail: cjy@ewha.ac.krEwha Womans University, Republic of Korea
} 
effects of teacher learning communities on elementary schools' effectiveness and explored the social and administrative factors within schools that can promote these communities. Specifically, in the present study, we addressed the following two research questions. How do PLCs in Korea affect schools' effectiveness and what are the school factors that affect PLCs in Korea?

\section{Literature Review}

\section{Analysis of previous research on the effects of PLCS}

Several empirical studies (e.g., Bryk, Camburn, \& Louis, 1999; DuFour, DuFour, \& Eaker, 2008; Dufour, 2011; Linder, Post, \& Calabrese, 2012; McLaughlin \& Talbert, 2001; Newmann, 1996; Thessin \& Starr, 2011) that highlighted the importance of PLCs have consistently provided evidence that these communities can be important instruments for improving teachers' instructional activities. Researchers maintain that teachers can improve their instructional activities in PLCS in which school goals are shared and colleague collaboration is well established. Newman (1996) found that in school cultures that emphasize cooperative learning among teachers, teachers come to know how they can obtain more learning opportunities through cooperation with their colleagues, and they apply their knowledge more often to the cooperative learning that takes place among students in their classes. These schools actively support the teachers' professional experiment, and have the strong belief that the failure of new attempts will contribute to the professional growth of their teachers. Therefore, in these school cultures, teachers attempt innovative teaching methods that live up to new educational processes and attempting to actively change their teaching contexts.

Recent studies have explored effective PLCs, observing that teachers in these communities show a strong desire to try new things and engage in different, more collaborative instructional activities. For instance, Dufour (2011) found that teachers in effective PLCs participate actively in learning opportunities and thus improve the quality of their teaching activities. That author showed PLCs can help teachers to rethink their teaching practices, challenge extant assumptions about teaching methods, and reexamine the learning needs of their students. Strong PLCs emphasizes innovation and inquiry and organize teachers' learning opportunities and instructional activities on a cooperative rather than individual basis. Teachers in these communities have a strong belief that all students have the ability to learn, and they steadily pursue new initiatives to improve their instructional activities.

Thessin and Starr (2011) showed that the effectiveness of school reforms in improving teachers' instructional activities varies according to the nature of the teacher learning community within the school. The researchers found that the shared norms and collaborative relationships in a PLC mediated the effects of school reform and policy. For example, teachers in a strong PLC believed that their colleagues tended to be open to innovation, to be respectful towards one another, and provide ample support and good advice for their instructional activities. In these schools, teachers share resources and information needed to carry out new instructional activities proposed by school reforms, devise new activities together, and undertake professional learning about the contents of the reforms. By contrast, schools with weak teacher communities tend to be conservative toward change, and their teachers are markedly individualistic and have low expectations in regard to student learning. In these schools, efforts to improve these teachers' instructional activities are isolated and few. Moreover, what the teachers learn in these schools is often irrelevant to the contents of reforms.

PLCs have also been shown to affect students' academic performance. Specifically, they have positive effects on teachers' instructional activities, which can lead to improved students' academic performance in students (Katz \& Earl, 2010; Linder, Post, \& Calabrese, 2012; Newman, 1996). Studies define the effectiveness of PLCS in terms of their ultimately leading to students' improved academic performance. The positive effects of PLCs on students have been mentioned constantly over the past two decades. For instance, Newman (1996) found that students who attended schools with PLCs that emphasize teaching-learning activities have higher academic achievement in mathematics and social studies than do students who attend schools that do not. Recently, Katz and Earl (2010) found that when teachers participated in PLCs, there are significant positive changes in their schools, which results in academic improvement in their students. Researchers maintain that mere membership in a PLC is not sufficient to have a positive impact on school innovation or student achievement. Only teachers' intensive and continuous participation in PLCs can lead to improvements in their students' academic performance.

\section{Previous research on factors affecting PLCS}

Teachers are influenced by the administrative environments of their schools, such as their organizational structures and operation. PLCs can be directly affected not just by the external features of school organization, but also the different leadership styles of different school principals, the distribution of authority, and the schools' social resources and programs.

\section{Principal leadership}

It is often assumed that schools' learning environments can be configured differently according to the principal leadership and that this can also have a significant impact on PLCs. It is expected in academia that the supportive leadership of principals will be related to PLCs, and empirical studies (e.g., Hallinger \& Heck, 2010; Knapp, Copland, Honig, Plecki, \& Portin, 2010; Kurland, Peretz, \& Hertz-Lazarowitz, 2010) are being conducted to verify this. Principals who demonstrates supportive leadership can provide PLCs with space and equipment along with necessary resources and financial support. In positive learning environments that are thus supported by principals, teachers should have significant learning opportunities. 


\section{Teacher autonomy}

The extent to which teachers can influence work-related decisions at their schools can affect PLCs. Easton (2012) found that teachers in learning communities learned better when they had opportunities to deliberate on what they should do and how exactly to get organized in relation to school goals. Firestone and Pennell (1993), and more recently Hunzicker (2011), maintained that granting teachers decision-making authority is important because it can promote trust in their organization as well as fairness. It can be expected that participating in such decision-making can have a positive impact on PLCs.

\section{Teacher learning support}

Several studies (e.g., Leclerc, Moreau, Dumouchel, \& Sallafranque-St. Louis, 2012) indicate that PLCs can flourish in work environments that provide material support for teacher learning. In general, providing appropriate teaching materials and support for teacher training are important for enabling teachers to dynamically organize their social relations in the workspace that is their school. In particular, support for teacher training can be arranged and implemented right in the school where the teachers work in order to improve their professional quality, and it is possible to improve the teachers' professionalism through interaction with colleagues and participation in collaborative research communities.

\section{Supportive relationships among teachers}

Teachers can strengthen their PLCs through conversations that go beyond friendly dialogues and that revolve around the value of learning (Leclerc, Moreau, Dumouchel, \& Sallafranque-St. Louis, 2012; Linder, Post, \& Calabrese, 2012). Through such conversations, they can share the value of emphasizing innovative ideas and trying new teaching methods in order to improve teaching activities. Although friendliness is a fundamental element in maintaining cordial conversations among teachers, their conversations should be related to teaching and learning activities. By discussing with their colleagues the key issues that arise in their teaching activities, teachers can strengthen the kind of learning community in which they can share their professionalism with one another. For this reason, we take relationships among teachers to be another important factor in promoting PLCs.

\section{Time Resources}

The importance of time as a resource for collaboration among teachers is emphasized in the relevant literature. Caskey and Carpenter (2012) argued that time for collaboration among teachers is an important condition for facilitating PLCs. Only when teachers in PLCs are given this collaboration time can they discuss the importance of continuing professional growth and participate in collaborative learning with colleagues. Time can pose a problem for teachers who want to collaborate and share ideas with their colleagues (Guskey, 2009; Hunzicker, 2011; Leclerc et al., 2012; Sanchez, 2012). Empirical studies (e.g., Leclerc et al., 2012; Thornburgh \& Mungai, 2011; Thornton, 2010) have generally found that teachers who take part in PLCs need additional time to learn and collaborate with other teachers.

\section{Communication systems}

Despite the fact that school facilities exert a direct or indirect influence on PLCs, there is an extreme dearth of studies on this matter. However, Riehl and Sipple (1996) presented analysis results that communication facilities in schools have a significant impact on teachers' professional commitment.

\section{Research model and hypotheses}

Based on literature review, this study proposed the hypothesized model shown in Figure 1.

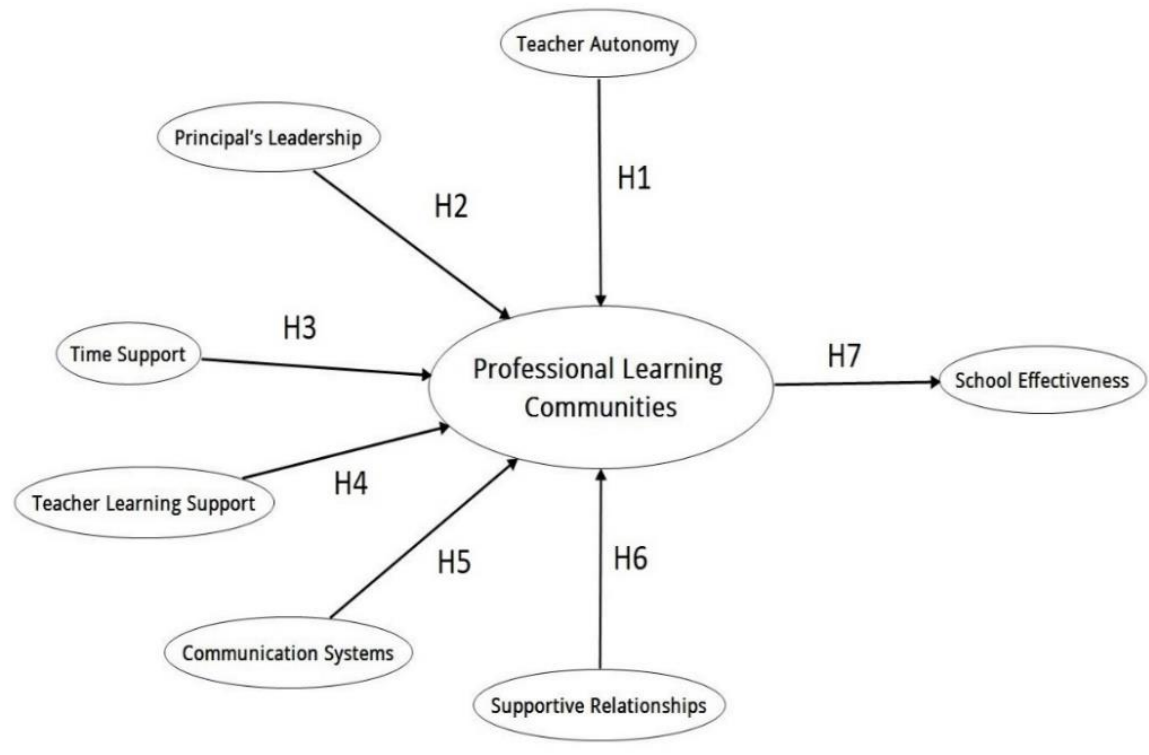

Figure 1. The proposed research model with hypotheses. 


\section{Research Methods}

\section{Participants}

We distributed 400 questionnaires to 40 elementary schools in Seoul, South Korea, and ultimately received 375 valid questionnaires for used in the date analysis for the study. The sample consisted of 82.1 percent females and 17.9 percent males. 85.9 percent of the teachers taught in the public schools, whereas 14.1 percent taught in private schools. The average number of years of teaching experience was 11.69 .8 percent of the teachers held bachelor's degrees, and 30.2 percent held a master's or higher degrees.

\section{Instrument}

For this study, we used a questionnaire survey to collect the data. Prior to the survey, we conducted a pilot test by asking 10 elementary teachers to respond to the first survey. The results of this pilot test indicated that we needed to make minor corrections in the questionnaire wording. Once we made the revisions, we conducted the final survey. The questionnaire comprised three parts. The first one included the items measuring teachers' perceptions of the professional learning communities at their schools. For this purpose, we adopted items from the Professional Learning Community Assessment Questionnaire (PLCAQ) developed by Huffman and Hipp (2003). Specifically, we selected the items that measured four dimensions of PLCs to measure the communities; we separated out the dimension that measured support condition and used to measure the factors that influenced PLCs. The items that measured PLCs were scored in a sixpoint Likert scale from 1(strongly disagree) to 6(strongly agree). The four dimensions were shared vision (nine items), shared leadership (eleven items), collective learning (ten items), and shared practice (seven items).

The second section of our survey comprised eight items that measured teachers' perceptions of their schools' effectiveness; we adopted the items of the school effectiveness scale developed and validated by Hoy (2009), all of which were scored in a six-point Likert scale. The third sections' items measured teachers' perceptions of the factors that influenced PLCs in their schools. The items fall into six categories: principal's leadership (eight items), teacher autonomy (seven items), time support (two items), teacher learning support (two items), communication systems (three items), and supportive relationship (five items). We adapted the items that measured time, learning, and information support, and supportive relationships from the PLCAQ and presented them on a six-point Likert scale.

\section{Data analysis}

We analyzed the survey data in the following steps. First, we obtained preliminary statistics using SPSS, running descriptive statistics to screen the data and determine the distributional characteristics of each variable. Next, we examined correlations among variables and conducted reliability analyses using Cronbach's alpha to test the internal reliability of each construct. Finally, using AMOS, we ran structural equation modeling (SEM) to test the adequacy of the hypothesized model. The structural equation model consisted of two sub-models, one for measurement and one structural. We conducted confirmatory factor analysis (CFA) to determine whether the measurement model fits the data, using a number of fit indices: the chi-square statistic adjusted by the degrees of freedom ( $x 2 / d f)$, the Tucker-Lewis index (TLI), the comparative fit index $(\mathrm{CFI})$, the incremental fit index (IFI), and the Root Mean Square Error of Approximation (RMSEA).

We assessed convergent validity by checking factor loadings and the average variance extracted (AVE), and we also calculated the composite reliability (CR). We assessed discriminant validity by inspecting the correlations among the constructs and the AVEs. Once the measurement model fit was acceptable, we tested the structural model. This entailed included testing the structures between the constructs as well as testing the overall fit of the hypothesized model. We evaluated the structural model fit using the fit indices and, if needed, modified the initial model using the modification indices (MLs).

\section{Results}

\section{Descriptive statistics}

Table 1 shows the descriptive statistics for the research variables. First, the mean scores of the factors that influenced PLCs ranged from 3.85 to 4.36 on the six-point Likert scales. The mean for teacher learning support was the highest $(M=4.38)$, and that for communication systems was the lowest $(M=3.85)$. The mean scores for principals' leadership and teacher autonomy were both lower than 4 , reflecting the teachers' negative perceptions regarding these factors. Second, the mean scores for the four PLC dimensions ranged from 3.80 to 4.48 , with the means for shared vision and shared leadership being lower than those for collective learning and shared practices. In particular, the mean for shared leadership lower than 4, indicating teachers' negative responses about this dimension. Third, the mean scores for school effectiveness was 4.45 in a six-point Likert scale.

\section{Structural equation modeling results}

We first examined the measurement model to validate and refine the research instrument and then ran the structural model to test the relationships in our hypothesized model.

\section{Measurement model}

We estimated the measurement model using the maximum likelihood method to examine the hypothesized relationships between observed variables and the underlying constructs. Our initial results for the overall fit test indicated unacceptable model fit with the data $(X 2=2131.14, d f=672, p<.0001, \chi 2 / d f=3.17, C F I=.88$, $\mathrm{TLI}=.86, \mathrm{IFI}=.88$, and RMSEA $=.08)$. To identify the causes of poor fit, we examined the Mls. We examined the item pairs with high Mls and decided to keep these items because they were important for measuring their respective constructs and because they appeared to 
correlate with each other. Thus, we considered it appropriate to re-estimate the model with the error covariance between the item pairs. Goodness-of-fit indices for the modified measurement model indicated significant improvement $(\chi 2 / d f=1750.44, d f=668, p<$ $.0001 ; \Delta 389.7 / 4, p<.001)$, and the modified model showed acceptable fit $(\mathrm{X} 2 / \mathrm{df}=2.62, \mathrm{CFI}=.91, \mathrm{TLI}=.90, \mathrm{IFI}=$
.91 , and RMSEA $=.07)$. Inspection of the standardized parameter estimates indicated that all items loaded significantly on their respective constructs; the factor loadings for all items in each construct ranged from .60 to .90 , which exceeded the recommended level of .60 . Table 2 displays the CFA results.

Table 1. Descriptive statistics for the research variables

\begin{tabular}{|c|c|c|c|c|c|}
\hline Construct & $\mathrm{N}$ & Min. & Max. & Mean & SD \\
\hline Principal's leadership & 375 & 1.00 & 6.00 & 3.94 & 1.10 \\
\hline Teacher autonomy & 375 & 1.00 & 6.00 & 3.99 & 0.99 \\
\hline Time support & 375 & 1.00 & 6.00 & 4.01 & 1.05 \\
\hline Teacher learning support & 375 & 1.00 & 6.00 & 4.38 & 0.98 \\
\hline Communication systems & 375 & 1.00 & 6.00 & 3.85 & 1.09 \\
\hline Supportive relationship & 373 & 1.60 & 6.00 & 4.24 & 0.89 \\
\hline \multicolumn{6}{|l|}{ PLCs } \\
\hline Shared vision & 375 & 1.00 & 6.00 & 4.09 & 1.03 \\
\hline Shared leadership & 375 & 1.44 & 6.00 & 3.80 & 0.89 \\
\hline Collective learning & 375 & 1.00 & 6.00 & 4.39 & 0.89 \\
\hline Shared practices & 375 & 1.00 & 6.00 & 4.48 & 0.89 \\
\hline School effectiveness & 373 & 1.75 & 6.00 & 4.45 & 0.75 \\
\hline
\end{tabular}

Table 2. Confirmatory factor analysis results

\begin{tabular}{|c|c|c|c|c|}
\hline Construct/Item & Standardized loading & $\begin{array}{r}\text { Cronbach's } \\
\text { Alpha }\end{array}$ & CR & AVE \\
\hline PLCs & & .89 & .88 & .66 \\
\hline Shared vision & .855 & & & \\
\hline Shared leadership & .866 & & & \\
\hline Collective learning & .798 & & & \\
\hline Shared practices & .709 & & & \\
\hline Teacher autonomy & & .91 & .91 & .60 \\
\hline Teacher autonomy 1 & .614 & & & \\
\hline Teacher autonomy 2 & .712 & & & \\
\hline Teacher autonomy 3 & .857 & & & \\
\hline Teacher autonomy 4 & .883 & & & \\
\hline Teacher autonomy 5 & .783 & & & \\
\hline Teacher autonomy 6 & .778 & & & \\
\hline Teacher autonomy 7 & .742 & & & \\
\hline Principal's leadership & & .94 & .93 & .64 \\
\hline Principal's leadership 1 & .775 & & & \\
\hline Principal's leadership 2 & .825 & & & \\
\hline Principal's leadership 3 & .832 & & & \\
\hline Principal's leadership 4 & .852 & & & \\
\hline Principal's leadership 5 & .681 & & & \\
\hline Principal's leadership 6 & .819 & & & \\
\hline Principal's leadership 7 & .790 & & & \\
\hline Principal's leadership 8 & .808 & & & \\
\hline Time support & & .85 & .85 & .74 \\
\hline Time support 1 & .841 & & & \\
\hline Time support 2 & .880 & & & \\
\hline Teacher learning support & & .83 & .83 & .71 \\
\hline Teacher learning support 1 & .790 & & & \\
\hline Teacher learning support 2 & .895 & & & \\
\hline
\end{tabular}


Table 2. (Continue)

\begin{tabular}{|c|c|c|c|c|}
\hline Communication systems & & .90 & .90 & .76 \\
\hline Communication systems 1 & .872 & & & \\
\hline Communication systems 2 & .890 & & & \\
\hline Communication systems 3 & .847 & & & \\
\hline Supportive relationship & & .89 & .89 & .62 \\
\hline Supportive relationship 1 & .683 & & & \\
\hline Supportive relationship 2 & .847 & & & \\
\hline Supportive relationship 3 & .743 & & & \\
\hline Supportive relationship 4 & .826 & & & \\
\hline Supportive relationship 5 & .822 & & & \\
\hline School Effectiveness & & .91 & .91 & .56 \\
\hline School Effectiveness 1 & .643 & & & \\
\hline School Effectiveness 2 & .602 & & & \\
\hline School Effectiveness 3 & .821 & & & \\
\hline School Effectiveness 4 & .785 & & & \\
\hline School Effectiveness 5 & .806 & & & \\
\hline School Effectiveness 6 & .763 & & & \\
\hline School Effectiveness 7 & .760 & & & \\
\hline School Effectiveness 8 & .793 & & & \\
\hline
\end{tabular}

We assessed reliability and validity by the following ways. First, we measured the internal consistency of the constructs with Cronbach's Alpha, and all the Cronbach's Alpha ranged from .83 to 94 , showing that all the constructs had acceptable internal consistency. Second, the CRs ranged from .83 to .93 , which exceeded the recommended level of .80. Third, the AVEs ranged from .56 to .76 , which also exceeded the recommended level of .50. Thus, the results indicated good convergent validity for the items. Table 2 shows the CFA results, the CRs for each construct, and the AVEs. Finally, we tested discriminant validity by comparing the correlations between two constructs with the square roots of their respective AVEs. Table 3 shows the correlations of each construct pair and the square roots of AVEs; the AVEs for each construct are shown along the diagonal. As shown in the table, no correlations exceeded the square roots of their AVEs, demonstrating sufficient discriminant validity.

Table 3. Correlation coefficients and the square roots of average variances extracted

\begin{tabular}{|c|c|c|c|c|c|c|c|c|}
\hline Construct & PLCs & $\begin{array}{l}\text { Teacher } \\
\text { Autonomy }\end{array}$ & $\begin{array}{l}\text { Principal's } \\
\text { leadership }\end{array}$ & $\begin{array}{l}\text { Time } \\
\text { Resources }\end{array}$ & $\begin{array}{l}\text { Time } \\
\text { support }\end{array}$ & $\begin{array}{l}\text { Teacher } \\
\text { learning } \\
\text { support }\end{array}$ & $\begin{array}{l}\text { Supportive } \\
\text { relationships }\end{array}$ & $\begin{array}{l}\text { School } \\
\text { effectiveness }\end{array}$ \\
\hline PLCs & $.81 *$ & & & & & & & \\
\hline $\begin{array}{l}\text { Teacher } \\
\text { autonomy }\end{array}$ & .67 & $.77^{*}$ & & & & & & \\
\hline $\begin{array}{l}\text { Principal's } \\
\text { leadership }\end{array}$ & .84 & .55 & $.80 *$ & & & & & \\
\hline Time support & .80 & .49 & .52 & $.86^{*}$ & & & & \\
\hline $\begin{array}{l}\text { Teacher } \\
\text { learning } \\
\text { support }\end{array}$ & .62 & .47 & .55 & .58 & $.84^{*}$ & & & \\
\hline $\begin{array}{l}\text { Communication } \\
\text { systems }\end{array}$ & .85 & .61 & .62 & .77 & .65 & $.87^{*}$ & & \\
\hline $\begin{array}{l}\text { Supportive } \\
\text { relationships }\end{array}$ & .86 & .56 & .56 & .76 & .53 & .77 & $.79 *$ & \\
\hline $\begin{array}{l}\text { School } \\
\text { effectiveness }\end{array}$ & .73 & .50 & .51 & .58 & .51 & .66 & .71 & $.75^{*}$ \\
\hline
\end{tabular}

*Square roots of average variances extracted

\section{Structural model}

Because the measurement model fit was acceptable, we tested the modified structural model to examine the relationships among the constructs, using the maximum likelihood method. The overall goodness-of-fit indices shows that the structural model fit the data well $(\chi 2=$
1774.75, $d f=674, p<.001, \chi 2 / d f=2.63, \mathrm{CFI}=.91, \mathrm{TLI}=.89$, $\mathrm{IFI}=.91$, and RMSEA $=.07$ ). Thus, we accepted this model as the final model for this study and examined the estimated coefficients of the relationships between constructs. 
The hypothesis testing results showed that all hypotheses except one (H4) were supported. First, the direct effects of teacher autonomy, principal's leadership, time support, information support, and supportive relationships on PLCs $(H 1, H 2, H 3, H 5, H 6)$ were statistically significant. Second, the direct effect of learning support on PLCs (H4) was insignificant. Third, among the factors, the direct effect of supportive relationships on PLCs was the highest Table 4. Results of the SEM analysis $(\beta=.39, \mathrm{t}=6.98, p<.001)$, and the second highest was for principal's leadership $(\beta=.37, t=9.41, p<.001)$. Fourth, the direct effect of PLCs on school effectiveness $(\mathrm{H} 7)$ was positive and significant $(\beta=.73, t=11.08, p<.001)$, showing that PLCs plays an important role in promoting school effectiveness. Table 4 shows the results of the hypothesis testing.

\begin{tabular}{llrrr}
\hline Hypothesis & Path & $\begin{array}{r}\text { Standardized } \\
\text { Estimate }\end{array}$ & Critical ratio & Result \\
\hline 1 & Teacher autonomy $\rightarrow$ PLCs & .07 & $2.15^{*}$ & Support \\
2 & Principal's leadership $\rightarrow$ PLCs & .37 & $9.41^{* * *}$ & Support \\
3 & Time support $\rightarrow$ PLCs & .15 & $2.94^{* *}$ & Support \\
4 & Teacher Learning Support $\rightarrow$ PLCs & -.02 & -.43 & Reject \\
5 & Communication systems $\rightarrow$ PLCs & .18 & $3.12^{* *}$ & Support \\
6 & Supportive relationship $\rightarrow$ PLCs & .39 & $6.98^{* * *}$ & Support \\
7 & PLCs $\rightarrow$ School effectiveness & .73 & $11.08^{* * *}$ & Support
\end{tabular}

${ }^{*} p<.05 ;{ }^{* *} p<.01 ; * \star * * 0.001$

Table 5 shows the standardized indirect and total effects of the influential factors and PLCS on school effectiveness, and principals' leadership and supportive relationships

that is, principal's leadership and supportive relationships were important for enhancing school effectiveness. indirectly influenced school effectiveness through PLCs;

Table 5. Standardized indirect and total effects of the factors and PLCS on school effectiveness

\begin{tabular}{lrr}
\hline Path & $\begin{array}{r}\text { Standardized } \\
\text { indirect effect }\end{array}$ & $\begin{array}{r}\text { Standardized } \\
\text { total effect }\end{array}$ \\
\hline Teacher autonomy $\rightarrow$ PLCs $\rightarrow$ School effectiveness & .05 & .05 \\
Principal's leadership $\rightarrow$ PLCs $\rightarrow$ School effectiveness & .27 & .27 \\
Time support $\rightarrow$ PLCs $\rightarrow$ School effectiveness & .11 & .11 \\
Teacher Learning Support $\rightarrow$ PLCs $\rightarrow$ School effectiveness & -.01 & -.01 \\
Communication systems $\rightarrow$ PLCs $\rightarrow$ School effectiveness & .13 & .13 \\
Supportive relationship $\rightarrow$ PLCs $\rightarrow$ School effectiveness & .28 & .28 \\
PLCs $\rightarrow$ School effectiveness & - & .73 \\
\hline
\end{tabular}

\section{Discussion and Conclusion}

In this study, we verified that the effects of PLCs in Korean elementary schools are consistent with the findings from previous studies conducted in other countries. Ours can be considered the first study using Korean data to determine what features of school organizations contribute to making PLCs effective. We provided empirical evidence that these organizational features ultimately support innovation in school organization.

Although we could not provide direct evidence that PLCS can improve student achievement, the positive causal relationship between PLCs and the school effectiveness variable could be seen as predicting a positive relationship between PLCs and academic achievement. These results are consistent with the conclusions of previous studies. Over the last two decades, previous studies (e.g., Barton \& Stepanek, 2012; Guskey 1997; Harris \& Jones, 2010) have found that teachers' attitudes and beliefs change when they directly observe how changes in teaching practice affect student learning. In PLCs in which teachers and administrators share their underlying values and visions about student learning, and in cultures that accepts new attempts and failures, teachers will strive harder to make their schools learning organizations and to meet their students' learning needs. 
In this light, with the present study, we provide assurance of the meaningful role of PLCs in improving student academic performance and in leading school reforms.

The study also provides significant evidence of the organizational features of schools that can stimulate PLCS and ultimately lead to changes in school organizations. First, principals' leadership and social relationships among teachers are important contributors to effective PLCs. Teaching practice and student achievement can be improved in PLCS in which support is provided by the school principal and social relationships are maintained that can have repeated impact on colleagues through reflective discussion and collaborative activities. In contrast, teachers who do not want any intervention in their current affairs will actively oppose changes, and the principal's leadership can eventually become ineffective. Previous studies have already shown that supportive principal leadership can encourage collaborative relationships among teachers (Firestone et al., 2005; Little, 1999; Supovitz \& Christman, 2003). It is difficult to confirm that supportive principals are directly linked to changes in teaching practice, but by promoting PLCs, the principals can affect teachers' access to effective learning opportunities.

Second, although this study only reveals a weak influence, teacher autonomy also has a positive effect on PLCs. In other words, PLCs can be more effective when they can wield the collective influence of teachers in school policies and teaching activities. There are already many studies that agree with these findings (Little, 1990; Marks \& Louis, 1999; Newmann, 1993; Smlylie, 1994). Granting collective decision-making authority to teachers has a positive effect on PLCs and can play an important role in developing teachers' professionalism. As teachers experience collective autonomy, they have the opportunity to reexamine their current assumptions about instructional activities and to increase their sense of responsibility for professional growth.

Third, this study shows that structural features within schools such as time support and communication systems are important influences on PLCs. Time support and communication systems can improve the abundance of the above-mentioned social resources in schools. Time as a resource can make it easier for teachers to collaborate, and social trust can be stronger when teachers have opportunities for face-to-face interactions with each other. Socializing with new school members may occur more frequently when teachers are given the time resources for development such as individual mentoring along with official orientation programs. Time resources can effectively encourage individual acts of care among teachers and foster the generation and maintenance of PLCs in schools. However, it is not the case that PLCs will necessarily come into existence with time; time is just one feature of the work environment that facilitates PLCs. Nevertheless, time resources can provide opportunities for school members to come together, and in this sense, time can be an important structural factor in the success of PLCS.
In future research, it will be important to observe more closely how PLCs arise and are maintained the school level. With this study, we explored some variables that foster PLCs, but a longitudinal study on the processes of change in schools can provide more rigorous confirmation of the hypotheses of this study. Furthermore, by observing the processes that transpire in Korean PLCs through case analyses, we can arrive at a deeper understanding of these learning communities in Korea.

\section{References}

Barton, R., \& Stepanek, J. (2012). The impact of professional learning communities. Principal's Research Review, 7(4), 1-4.

Bryk, A., Camburn, E., \& Louis, K. S. (1999). Professional community in chicago elementary schools: Facilitating factors and organizational consequences. Educational Administration Quarterly, 35, 751-781.

Caskey, M. M., \& Carpenter, J. (2012). Organizational models for teacher learning. Middle School Journal, 43(5), 52-62.

Dufour, R. (2011). Work together: But only if you want to. Phi Delta Kappan, 92(5), 57-61.

Dufour, R., Dufour, R., \& Eaker, R. (2008). Revisiting professional learning communities at work: New insights for improving schools. Bloomington, IL: Solution Tree Press.

Easton, L. B. (2012). Principles of design energize learning communities: Practical tips put the emphasis on learning. Journal of Staff Development, 33(4), 49-54.

Firestone, W. A., Mangin, M. M., Martinez, M. C., \& Polovsky, T. (2005). Leading coherent professional development: A comparison of three districts. Educational Administration Quarterly, 41(3), 413-448.

Firestone, W. A., \& Pennell, J. R. (1993). Teacher commitment, working conditions, and differential Incentive policies. Review of Educational Research, 63(4), 489-525.

Guskey, T. R. (1997). Research needs to link professional development and student learning. Journal of Staff Development, 18(2), 36-40.

Guskey, T. R. (2009). Closing the knowledge gap on effective professional development. Educational Horizons, 87(4), 224-233.

Hallinger, P., \& Heck, R. H. (2010). Collaborative leadership and school improvement: Understanding the impact on school capacity and student learning. School Leadership and Management, 30(2), 95-110.

Harris, A., \& Jones, M. (2010). Professional learning communities and system improvement. Improving Schools, 13(2), 172-181. 
Hoy, W. K. (2009). School Effectiveness Index. Retrieved from http://www.waynekhoy.com/ school_effectiveness_index.html.

Huffman, J.B., \& Hipp, K. K., (2003). Reculturing schools as professional learning communities. Lanham, Maryland: Scarecrow Education.

Hunzicker, J. (2011). Effective professional development for teachers: A checklist. Professional Development in Education, 37(2), 177-179.

Katz, S., \& Earl, L. (2010). Learning about networked learning communities. School Effectiveness and School Improvement, 21(1), 27-51.

Knapp, M. S., Copland, M. A., Honig, M. I., Plecki, M. L., \& Portin, B. S. (2010). Learning-focused leadership and leadership support: Meaning and practice in urban systems. Seattle, WA: Center for the Study of Teaching and Policy-University of Washington.

Kurland, H., Peretz, H., \& Hertz-Lazarowitz, R. (2010). Leadership style and organizational learning: The mediate effect of school vision. Journal of Educational Administration, 48(1), 7-30.

Leclerc, M., Moreau, A. C., Dumouchel, C., \& SallafranqueSt. Louis, F. (2012). Factors that promote progression in schools functioning as professional learning community. International Journal of Education Policy \& Leadership, 7(7), 1-14.

Linder, R. A., Post, G., \& Calabrese, K. (2012). Professional learning communities: Practices for successful implementation. Delta Kappa Gamma Bulletin, 78(3), 13-22.

Little, J. W. (1990). The persistence of privacy: Autonomy and initiative in teachers' professional relations. Teachers College Record, 91(4), 509-536.

Little, J. W. (1999). Teachers' professional development in the context of high school reform: Findings from a three-year study of restructuring schools. Washington, D. C.: National Partnership for Excellence and Accountability in Teaching.

Little, J. W. (2003). Inside teacher community: Representations of classroom practice. Teachers College Record, 105(6), 913-945.

Marks, H. M., \& Louis, K. S. (1999). Teacher empowerment and the capacity for organizational learning. Educational Administration Quarterly, 35, 707-750.

McLaughlin, M. W., \& Talbert, J. E. (2001). Professional communities and the work of high school teaching. Chicago: University of Chicago Press.
Newmann, F. M. (1993). Beyond common sense in educational restructuring: The issues of content and linkage. Educational Researcher, 22(2), 4-13.

Newmann, F. M. (1996). Center on organization and restructuring of schools: Activities and accomplishments, 1990-1996. Final report. Madison, WI: Center on Organization and Restructuring of Schools.

Riehl, C. \& Sipple, J. W. (1996). Making the most of time and talent: Secondary school organizational climates, teaching task environments, and teacher commitment. American Educational Research Journal, 33(4), 873-893.

Sanchez, B. (2012). Effective professional development: Teachers' perspectives on the south Texas writing project summer institute. National Teacher Education Journal, 5(2), 45-49.

Seo, K.-H. (2009). Teacher Learning Communities and Professional development. The Korean Society for the study of teacher education, 26(2), 243-276.

Smylie, M. A. (1994). Redesigning teachers' work: Connections to the classroom. Review of Research in Education, 20, 129-177.

Song, K.-O. \& Choi, J.-Y. (2010). Analysis on the measurement model and the level of professional learning community in elementary and secondary schools. The Korean Society for the study of teacher education, 27(1), 179-201.

Supovitz, J. A., \& Christman, J. B. (2003). Developing communities of instructional practice: Lessons for Cincinnati and Philadelphia. CPRE Policy Briefs, pp. 1-9. Pennsylvania: University of Pennsylvania.

Teague, G. M., \& Anfara Jr., V. A. (2012). Professional learning communities create sustainable change through collaboration. Middle School Journal, 44(2), 5864.

Thessin, R. A. \& Starr, J. P. (2011). Supporting the growth of effective professional learning communities district wide. Kappan, 92(6), 48-54.

Thornburg, D. G., \& Mungai, A. (2011). Teacher empowerment and school reform. Journal of Ethnographic \& Qualitative Research, 5(4), 205-217.

Thornton, H. J. (2010). Excellent teachers leading the way: How to cultivate teacher leadership. Middle School Journal, 41(4), 36-43. 
This page is intentionally left blank www.iejee.com 